\title{
EL DiÁlogo TEXTUAL ENTRE AULULARIA DE PLAUTO Y EL AVARO DE MOLIÈRE
}

\author{
The textual dialogue between Aulularia by Plauto and El avaro by Molière
}

\section{Daniela Soledad Gonzalez*}

Los libros siempre hablan de otros libros y cada historia cuenta una historia que ya se ha contado (U. Eco).

\begin{abstract}
RESUMEN
Este artículo se basa en la noción de transtextualidad como característica esencial de toda obra literaria. Se analizan comparativamente dos comedias: Aulularia, de Plauto y El avaro de Molière. El análisis es hermenéutico y estilístico. Se observa que las obras se asemejan por tener como protagonista y blanco de su crítica social al personaje tipo del avaro. Además, las similitudes formales entre las comedias son numerosas: alta tensión dramática, reflejo de creencias y costumbres, lenguaje vivo y estilizado, personajes tipo, palizas, situaciones cómicas, críticas a determinados oficios/profesiones y predominio del papel del esclavo. Ambas obras retoman, además, lo antiguo y clásico: Plauto, lo heleno; Molière, lo grecorromano. Por último, el tema de las obras es el mismo. Teniendo en cuenta estas similitudes y la teoría de Genette en Palimpsestos, se concluye que la relación que se establece entre las obras es la de hipertextualidad indirecta o imitación. En particular, una especie de la imitación denominada forgerie. La causa de la existencia de esta relación de hipertextualidad entre las obras es, principalmente, la arquetipicidad propia del mundo antiguo, lo cual se aviene con el hecho de que Molière perteneció al movimiento literario denominado Neoclacisismo.
\end{abstract}

Palabras clave: hipertextualidad, Plauto, Molière, avaro.

\begin{abstract}
This article is based on the notion of transtextuality as an essential feature of any literary work. Two comedies are analyzed comparatively: Aulularia, by Plautus and The greedy man, by Molière. The analysis is hermeneutical and stylistic. It is observed that are similar comedies because they have the greedy man as a main character and target of their social critic. In addition, formal similarities between comedies are numerous: high dramatic tension, customs and beliefs exibition, living and stylized language, type characters, beatings, comic situations, criticism of certain occupations/professions and a predominant role of slaves. Both books also take up classic antiquity: Plautus, the Hellenic one; Molière, Greco-Roman one. Finally, both comedies subject is the same. Given these similarities and taking into account Genette's theory in Palimpsestos, it is concluded that the relationship established between comedies is indirect hypertextuality or imitation. In particular, a kind of imitation called forgerie. The reason for the existence of such relationship between comedies is primarily ancient world's arquetipicity, which suits with the fact that Molière belonged to the literary movement known as Neoclassicism.
\end{abstract}

Palabras clave: hipertextuality, Plauto, Molière, greedy man.

\footnotetext{
* Universidad Nacional de Cuyo y CONICET (Consejo Nacional de Investigaciones Científicas y Técnicas). Profesora en Lengua y Literatura. Argentina.

Correo electrónico: gonzalezdanielasoledad@yahoo.com.ar

Recepción: 09-05-2017 Aceptación: 06-06-2017
} 


\section{Introducción}

La literatura es un diálogo constante, no solo de escritores con lectores, sino también de textos entre sí. Hay quien afirma que toda la literatura está basada en una relación hipertextual (Genette, 1962, p. 19). Lo cierto es que implica al menos una relación de transtextualidad constante, pues los escritores poseen un bagaje literario ineludible que sustenta su escritura, y porque, en general, sus obras surgen como oposición y refuerzo de otros textos ficcionales; incluso, en el hecho de inscribirse en un movimiento literario determinado o crear uno nuevo hay transtextualidad.

Eurípides, por ejemplo, al escribir Las troyanas, recurre al formato y los recursos propios del género tragedia (por lo tanto, presentes en muchos otros textos) y reproduce la historia que ya existía en la tradición oral y en los poemas homéricos. Es más, su obra es otra visión de la misma historia, es una especie de contestación de la Ilíada y La odisea.

Molière, dramaturgo francés del siglo XVII, como buen neoclasicista, toma de la lectura de los clásicos pautas para la escritura de sus propias obras (que, por supuesto, no son copias, sino construcciones verdaderamente propias). En el presente trabajo, se analizará la comunicación que se establece entre Aulularia (o La ollita o La marmita) de Plauto comediógrafo romano que vivió entre los siglos III y II a. C.- y El avaro (o Las tres monedas) de Molière.

Si bien el autor francés no hace una declaración explícita del uso de la fuente latina para su comedia (no era necesario), el asombroso parecido entre las obras revela que entre ellas existe una fuerte relación textual. Las obras presentan similitudes en la configuración genérica, el estilo, el tema y los recursos cómicos. Según el criterio establecido por Genette (1962) en Palimpsestos..., la relación existente entre las obras es de «hipertextualidad». Este tipo de diálogo ficcional se produce por la arquetipicidad propia de la Antigüedad Clásica.

\section{Plauto, vida y obra ${ }^{1}$}

Plauto (254 a. C.-184 a. C) nació en Sársina, pueblo montañés de Umbría, que desde hacía años estaba sometida a Roma. La región, bajo influencias etruscas y célticas, estaba poco latinizada. Debido a la pureza de su lengua, Plauto debió de haber llegado joven a Roma. También sabía griego.

\footnotetext{
${ }^{1}$ La información de este apartado se basa en Bayet (1975, p. 54-71).
} 
Activo y ambicioso, se ocupó del teatro, pero lo perdió todo al emprender un viaje marítimo comercial. Vuelto a Roma, se empleó en un molino. Tras un periodo de dura miseria, escribió tres comedias. Con ellas se impuso en la escena y pudo volver a escribir con desahogo. Murió, anciano, en el año 184 a. C.

Se le atribuyen 130 obras, pero hay acuerdo con respecto a la autenticidad para solo 21 de ellas. Algunas son: Pseudolus, Truculentus, Miles gloriosus, Cistellaria, Asinaria, Aulularia, Amphitruo, Trinumnus, Mercator, Mostellaria, Rudens, Stichus, Baccides, Menaechmi, Poenulus, Saturio y Addictus.

Plauto vivió y escribió su obra en la época literaria arcaica de Roma, que se extendió desde el año 249 al 88 a. C. durante esta etapa finalizó la segunda guerra púnica y cayó Anibal en la batalla de Zama ante Publio Cornelio Escipión. Comenzaron las guerras macedónicas y Roma tomó contacto con Oriente (Siracusa, Magna Grecia). Del contacto con lo griego se derivó la tendencia helenizante en Roma.

La poesía teatral estaba ligada a los ludi, juegos que se realizaban en las celebraciones religiosas anuales o para acrecentar los votos de los personajes públicos. Según Tito Livio, surgen para aplacar a los dioses y librarse de la peste del año 364 a. C. (Cfr. Bernardi \& Susa, 2008 , p. 61). La tragedia podía ser de contenido griego o romano, al igual que la comedia. Esta última se denominaba palliata cuando imitaba la comedia nueva ática y togata cuando era de tipo romano.

La palliata se estructuraba de la siguiente forma: al principio se ejecutaba un prólogo, que solía contener un planteo del tema de la obra y ubicar a los espectadores en una situación inicial; luego, se realizaban las partes dialogadas (diverbias), alternadas con partes cantadas (cantica).

\section{1. Características del teatro plautino}

Plauto toma elementos de los autores griegos de la comedia media como Antífanes, o de la comedia nueva, como Menandro. Transforma lo griego a través de la fuerza cómica romana. Las escenas son helenísticas en la palliata, al igual que las costumbres, la estructura social, los trajes y demás elementos.

La mayoría de las obras de Plauto se abre con un prólogo que presenta el tema de las obras. Allí, se exponen los eventos que han ocurrido previamente y lo que está por ocurrir en la representación (como guía para el espectador). Es recitado por un dios, un personaje alegórico, uno de los personajes de la comedia o un actor con un traje especial, llamado prologus. 
En Plauto, la acción no se ciñe al tema general. Preocupado por presentarla llena de vivacidad y sorpresas, pasa por alto algunos detalles, hace desaparecer y aparecer personajes a su gusto, alarga escenas, añade otras cuya idea le parece divertida, presenta bruscamente los desenlaces. No obstante, a pesar de la irregularidad de la acción, logra darle unidad a los episodios.

Los personajes que aparecen en las obras de Plauto son, en general, convencionales: el joven libertino y despilfarrador, la cortesana diestra, la joven modesta y simpática, el padre severo (pero con frecuencia ingenuo e inclinado a volver a sus hábitos de libertino), el traficante de esclavos, el parásito (que trata de obtener beneficios económicos con adulaciones), el cocinero de alquiler ladrón, entre otros. El más importante aquí es el avaro, «un hombre que hace innecesariamente difícil la vida para sí mismo y para los demás» (Staiger, 1966, p. 202).

El esclavo es muy importante en la comedia plautina. Es desvergonzado e ingenioso, desafía los golpes y está, a menudo, al servicio de los amores de su joven amo, no sin torturarlo en ocasiones. En efecto, el personaje que permite el avance de la acción en Aulularia es Estróbilo. Él es quien facilita el matrimonio de su amo con Fedria cuando devuelve a Euclión, padre de la doncella, el tesoro que le ha robado. Estróbilo está caracterizado como personaje burlesco y pícaro. Es bromista, inteligente, audaz. Espía a Euclión y se mofa de él haciéndole creer que nada sabe de su olla, lo sigue, y se apropia de ella, exponiéndose al peligro de ser descubierto y recibir una gran zurra: «Prefiero probar la suerte, aunque haya algún bastonazo» (Plauto, Aulularia, p. 63). Cuando le cuenta la hazaña a su amo y ve que este no se muestra dispuesto a negociar su libertad, niega todo sagazmente y se mantiene firme en su parvedad, desafiando nuevamente los golpes: «PPor Hércules, mátame si quieres, tampoco vas a obtener nada de mí!» (Plauto, Aulularia, p. 106).

Los personajes no son presentados siempre de la misma manera. A veces Plauto los caracteriza a través de monólogos y apartes, que dan rienda suelta a sus pensamientos y sentimientos. Estos monólogos dejan ver la coherencia o falta de ella entre lo que los personajes dicen y lo que hacen, además de los defectos/virtudes que no exteriorizan.

De vez en cuando, Plauto abusa de la libertad de la comedia para romper la ilusión referencial dirigiéndose al público. En Aulularia hay una interpolación de este tipo al inicio, en el prólogo del dios Lar: «Que nadie se pregunte quién soy ... El hombre murió y, ved su avaricia ... Pero ved ahora al viejo» (Plauto, Aulularia, p. 43). Hay otra interpolación más en la escena IX del acto IV, cuando Euclión pregunta a los espectadores quién le ha robado su ollita. Este recurso, claramente, persigue un efecto cómico, pues es una acción sorpresiva que desestabiliza al público, inmerso en el mundo ficcional. 
Plauto deja conforme al público romano, que pide que se le representen las costumbres griegas. Se preocupa por asegurarles en reiteradas ocasiones que no lo olvida, pero cree que un teatro vivo debe ser actual y él mismo se halla muy sumergido en Roma como para no retratar sus costumbres, organización y creencias de la época en lo relativo al tratamiento de los esclavos, al matrimonio, al deber de la esposa y la paternidad, a las comidas, etc. Es frecuente en él la crítica a ciertas profesiones y oficios, sobre todo a los cocineros, que eran considerados como ladrones.

Satisface los gustos más diversos de los habitantes del pueblo, delicados o groseros. La moral no le incumbe; incluso prefiere la desvergüenza como encanto del espectáculo. Sin embargo, su obra está empapada en un realismo romano, que siempre termina dejando en claro que la virtud es mejor, que el libertinaje arruina la juventud y que, aunque esta posea licencias, siempre se debe cuidar la reputación. Plauto tiene, además, una tendencia muy romana a la sátira de las profesiones malsanas o de los explotadores. En esto agrada a los estratos más bajos de la sociedad, dispuestos a la crítica.

En el uso que Plauto hace del lenguaje puede apreciarse su genialidad. Explota de modo excelente los medios que le ofrece el latín. Su lengua es pura, viva y popular, a la vez que estilizada. Logra expresar a menudo las ideas de la gente vulgar sin vulgaridad. Usa recursos como juegos de palabras, doble sentido, adivinanzas, malentendidos, refranes, encomendaciones a los dioses, paralelismos cómicos, apartes, monólogos y esticomitías. Otros recursos cómicos que utiliza el autor son los siguientes: exageraciones, palizas, repeticiones, ingenio grosero, bromas y arrebatos de insultos, entre otros.

\section{2. Aulularia}

La obra está organizada en un prólogo y cinco actos. El acto uno posee dos escenas; el acto dos, ocho; el acto tres, seis y el acto cuatro, diez. Lo que se ha podido conservar de la obra llega hasta la escena uno del quinto acto. El protagonista de la obra es un hombre viejo y avaro: Euclión. La obra trata de cómo su avaricia consume su vida y altera la de los demás. La acción transcurre en Roma.

A continuación, se desarrolla el argumento de la obra. Euclión encuentra en su casa, por gracia del lar de su familia y en atención a la piedad de su hija Fedria, una olla llena de oro. Vuelve a enterrarla y vigila hasta a su propia sombra para que no roben el tesoro. Fedria ha sido deshonrada por Licónides, hijo de Eunomia, y ha quedado embarazada. Mientras tanto, el tío de Licónides, el viejo burgués Megadoro, que ha sido persuadido por su hermana Eunomia para que tome esposa, pide en matrimonio a Fedria. El viejo gruñón apenas consiente la unión. 
Debido al alboroto que se arma en su casa por el convite de celebración, Euclión cambia el escondite de la olla, que lleva al templo de la Buena Fe. No advierte que Estróbilo, esclavo de Licónides, lo descubre y lo sigue. Este esclavo conoce la intención de su amo de casarse con Fedria. Cuando el viejo avaro encuentra al esclavo rondando por el templo, desconfía y lo lleva a otra parte, pero no se escapa del seguimiento del esclavo, que hurta la ollita. Finalmente, Licónides logra que Estróbilo restituya el caudal a Euclión y que su tío le ceda a la joven. Euclión celebra el matrimonio muy feliz junto a su amada ollita.

\section{Molière, vida y obra ${ }^{2}$}

Molière es el pseudónimo de Jean-Baptiste Poquelin (1622-1673), dramaturgo y actor francés. Nació en París, hijo de un rico tapicero. Desde pequeño le gustó el teatro, al que iba seguido con sus abuelos. Estudió Derecho. Ejerció pocos meses como abogado, luego sustituyó a su padre como tapicero real de Luis XIII y se relacionó con la familia Béjart. Esta familia creó una compañía, en la que Molière se incorporó. Molière, además, se casó con una joven de la familia.

La compañía, a la que Molière dio el nombre de L'Illustre Théâtre actuó en París hasta 1645 e inició un recorrido por Francia que duró trece años. A su regreso, la compañía contó con el apoyo de Luis XIV y se consagró como escritor, actor y director.

A pesar de contar con el apoyo real ${ }^{3}$, su éxito tuvo que tropezar con obstáculos. En 1659, estrenó Las preciosas ridículas. La obra satiriza las aspiraciones de dos jovencitas de provincia. Sin embargo, las mujeres mayores que se sintieron criticadas hicieron destruir el teatro. El rey tuvo que trasladar a Molière a otro teatro. No solo con las mujeres iba a tener inconvenientes: engendró, además, celos en otras compañías teatrales y escándalos con personas muy religiosas, que se escandalizaban ante las obsenidades e irreverencias de sus obras.

En cuanto a su estilo, Molière trabajó con el fin de alterar el estilo excesivamente espectacular y ampuloso del teatro francés de su época. Por ello, se caracteriza por un estilo coloquial y movimientos más naturales en sus personajes.

Entre las obras de Molière se encuentran: La escuela de mujeres (1662), Tartufo (1664; versión definitiva, 1669), El misántropo (1666), El avaro (1668), El médico a palos (1666), El burgués gentilhombre (1670) y El enfermo imaginario (1673).

\footnotetext{
${ }^{2}$ Para mayor información sobre la vida y obra de Molière, cfr. Domenech (1967) y Chávez Robledo et al. (2009, p. 39-40).

${ }^{3}$ Para más detalles sobre la relación entre Molière y Luis XIV y las discusiones que hay sobre el tema, cfr. Garçon (1979).
} 


\section{1. El teatro de Molière}

Los personajes cómicos de Molière resultan familiares a los aficionados del teatro. Las obras del francés, de hecho, se siguen representando en la actualidad y han sido traducidas a numerosas lenguas. Los dramas de Molière satirizan a muchos tipos sociales como los hipócritas, los cornudos, los donjuanes, los falsos sabios, los burgueses pretenciosos y los médicos impostores ${ }^{4}$. Alejado del ascetismo, su papel moralista se reduce a un simple castigo de las malas costumbres por medio del humor. Su teatro se caracteriza por una crítica mordaz a la sociedad.

Algunos de los temas de sus obras son la identidad (verdadera y falsa), la adulación y la falacia de los médicos. Por otro lado, si bien retoma los personajes tipo de la Commedia dell'Arte (v. gr., bufón, avaro), fue más allá del objetivo de esta escuela, que se basaba en palizas, caídas y colorido más que en el contenido de la obra ${ }^{5}$. Molière, en cambio, realizó ácidas observaciones sobre los defectos y actos inmorales del ser humano.

Otra influencia que puede encontrarse en la obra del francés es la de la Antigüedad Clásica, pues su teatro se inscribe en el clasicismo francés. En este movimiento atístico, «la creencia renacentista en la ordenación armónica del mundo se convertiría en un auténtico culto a la razón, como referencia e imitación de la Antigüedad»(Valverde, 1984, p. 24).

Literariamente, esto se manifestó en el accionar de las Academias, que transformaron el platonismo en un seco intelectualismo con las Reglas del arte. Se tomó la regla de las tres unidades de Aristóteles (de tiempo -12 horas-, de lugar y de acción) a la cual se añadieron otras reglas. En España, algunos dramaturgos las siguieron, pero sin éxito, lo que llevó a otros, como Lope de Vega, a no aplicarlas. En Francia, en el siglo XVII, estas teorías se convirtieron en reglas inexorables, respaldadas por el Rey Sol (Luis XIV) a través de la Academia Francesa, que juzgaba sobre el ajuste a ellas.

En cuanto al contenido, la poesía debía ser expresión de la moralidad oficial. Este punto explotaron autores como Racine (tragedia), Corneille (tragedia) y Molière. La vena cómica hace la moralina más llevadera en este autor.

El movimiento del neoclasicismo es un movimiento humanista, pues «consiste en la ocupación con la antigüedad, esto es, en un principio de la enseñanza y de la formación y

\footnotetext{
${ }^{4}$ Sobre la relación de Molière con los médicos, cfr. Chávez Robledo et al. (2009). Molière sufrió muchas enfermedades y no obtuvo cura satisfactoria de ellas, lo cual derivó en un escepticismo ante las posibilidades de la medicina.

${ }^{5}$ La Commedia dell'Arte fue un tipo de comedia similar a la farsa, que alcanzó popularidad en Francia en el s. XVI. Se trataba de la representación de comedias improvisadas, con personajes tipo y gran despliegue escénico. Para más detalles sobre la Commedia dell'Arte, cfr. Jordan (2010).
} 
cultura que utilizan los escritores griegos y romanos como la fuente y no como el nacimiento espiritual no superable del hombre» (Friedrich, 1973, p. 9). En otras palabras, se trata de un comportamiento que sigue la guía de los antiguos porque a ellos se les concede una sabiduría más profunda y esencial que a los contemporáneos. Es una «actitud espiritual según la cual las realizaciones magistrales del pasado son una inspiración y un punto de partida» (Fontán, 1974, p. 17).

El movimiento humanista surgió en Roma, que tomó de Grecia la filosofía, la literatura y otras artes, la valoración de la libertad equilibrada por la mesura, la sensibilidad y la religiosidad. De los romanos ha pasado este legado a los pueblos del occidente cristiano. Subyace en la lengua, en nuestro modo de escribir, en la preeminencia política de los varones, en la estimación de la belleza del hombre, de la sencillez y de la verdad, en los géneros literarios, en la arquitectura y, de forma más evidente, en todas las imitaciones artísticas de los periodos históricos clasicistas. Y esto porque «al espíritu antiguo le es ingénita una arquetipicidad tan elemental que siempre que las culturas salidas de él buscan su propia figura, le viene en su ayuda como la plena transformación del espíritu europeo» (Friedrich, 1973, p. $15)$.

\section{2. El avaro}

El avaro es una comedia escrita en prosa dividida en cinco actos, representada por Molière en 1668 y publicada al año siguiente. Su tema es la avaricia de Harpagón, que complica su vida y la de quienes lo rodean. La acción se desarrolla en París.

Harpagón es un avaro usurero que ha hallado una arqueta enterrada en el jardín de su casa y vive aterrorizado por el temor de que se la roben. Por su avaricia, dificulta los matrimonios de sus hijos con sus enamorados. A su hijo Cleanto le niega el dinero que le pide para casarse con Mariana y a su hija Elisa le busca como esposo a Anselmo, un anciano adinerado, que es padre de su enamorado Valerio y también de Mariana. Valerio, por su parte, ha ingresado como criado en la casa de Harpagón, a pesar de su condición de noble, para estar junto a ella. El miedo a perder la olla hace que el avaro despida a Flecha, el criado de su hijo, quien luego roba el tesoro. Mientras la policía investiga el robo, Valerio confiesa su amor.

Puestas las cartas sobre la mesa y declarada la verdadera identidad de Valerio, Anselmo reconoce a sus hijos y cede su matrimonio con Elisa a Valerio. Por su parte, Cleanto, que ha recibido la olla de manos de Flecha, la devuelve a su padre a cambio de dinero para su boda con Mariana. 


\section{El diálogo textual entre Aulularia y El avaro}

Entre Aulularia y El avaro se establece una relación de hipertextualidad. Genette (1962, p. 14) la define como «toda relación que une un texto B (que llamaré hipertexto) a un texto anterior A (al que llamaré hipotexto) en el que se injerta de una manera que no es la del comentario». Aclara inmediatamente: «como se ve en la metáfora se injerta y en la determinación negativa, esta definición es totalmente provisional» (Genette, 1962, p. 14). Más adelante, dilucida que se trata de una derivación que, al igual que la metatextual, da como resultado un texto B que no podría existir sin A, pero que no habla de A, sino que ha surgido por una transformación de este.

La transformación del hipotexto puede ser de dos modos: directa o simple e indirecta o por imitación. La primera, de la cual el ejemplo elegido por Genette es la relación entre la Odisea y el Ulysses de Joyce, consiste en el traslado de una acción a un escenario diferente (Dublín del siglo XX). También se podría citar como ejemplo la relación entre la Antígona de Sófocles y la de Leopoldo Marechal.

La imitación es un proceso más complejo, pues exige la constitución previa de un modelo de competencia genérica (por ejemplo, la épica) capaz de engendrar un número indefinido de performances miméticas. El ejemplo de Genette que ilustra este caso es la relación existente entre la Odisea y la Eneida. Cuentan historias diversas, pero muchas características de la segunda han sido inspiradas en la primera, en su tipo épico.

La oposición entre ambos tipos de transformación está en «decir lo mismo de otra manera/decir otra cosa de manera parecida» (Genette, 1962, p. 16). Joyce extrae un esquema de acción y relación de personajes y cuenta la misma historia que Homero con otro estilo. Virgilio cuenta la historia de Eneas (no de Ulises), pero lo hace a la manera de Homero.

El avaro de Molière deriva de Aulularia de Plauto por imitación, pues Molière toma de Plauto la forma de su comedia, el tipo del avaro y los recursos cómicos, para hacer una nueva comedia con una historia similar, aunque parecida en algunas situaciones.

Genette, además de diferenciar las transformaciones de las imitaciones, hace otra distinción: cada una de ellas puede ser lúdica, satírica o seria. La transformación seria es la trasposición y la imitación seria es denominada forgerie (Cfr. Genette, 1962, p. 41). Se explaya en esto Genette:

El pastiche es la imitación en régimen lúdico, cuya función dominante es el puro divertimento; la charge es la imitación en régimen satírico, cuya función dominante es 
la burla; la forgerie es la imitación en régimen serio, cuya función dominante es la continuación o la extensión de una realización literaria existente (Genette, 1962, p. 104).

El autor define la imitación seria como «el estado de un texto que se parece lo más posible a los del corpus imitado, sin nada que atraiga, de una forma o de otra, la atención sobre la operación mimética en sí misma o sobre el texto mimético, cuyo parecido debe ser tan transparente como sea posible, sin señalarse a sí mismo como parecido a, es decir, como imitación» (Genette, 1962, p. 106).

El hipertexto debe contener los mismos rasgos estilísticos que el original, pero también debe presentar rasgos nuevos en igual proporción, además de no tomar préstamos literales. Sobre este punto, el autor hace una valoración interesante: «No creo que ninguna forgerie satisfaga esta regla, pero ninguna, sin duda, intenta deliberadamente transgredirla» (Genette, 1962, p. 106).

En palabras simples, no se trata de una imitación perceptible como tal, como lo es la de la sátira y el pastiche (Cfr. Genette, 1962, p. 106), sino de la imitación de un estilo. Hasta aquí, El avaro cumple con todas las características propias de una forgerie; sin embargo, es necesario profundizar un poco más en qué consiste este tipo de imitación. Continúa Genette (1962, p. 258):

Creo haber mencionado ya la parte (evidente) de hipertextualidad mimética que entra en la construcción de tradiciones genéricas: como fenómeno de época que, entre otras cosas, lo es siempre, un género no responde solo a una situación y a un horizonte de expectativas históricamente situados; procede también ... por contagio, imitación, deseo de explotar o alterar una corriente de éxito.

El autor ejemplifica el juicio anterior con la novela picaresca española, cuya historia es una serie de diversas imitaciones de un modelo inicial, el Lazarillo de Tormes. En este juicio, está implícita la idea que estructura toda la teoría genettiana, expresada por el autor al inicio de su libro: los cinco tipos de transtextualidad no son clases estancas (Cfr. Genette, 1962, p. 17). Esta idea es ilustrada con el siguiente ejemplo: «la architextualidad genérica se constituye casi siempre, históricamente, por vía de imitación... y, por tanto, de hipertextualidad» (Genette, 1962, p. 106).

Siguiendo las últimas consideraciones realizadas, es posible terminar de caracterizar $E l$ avaro como imitación seria de Aulularia. El último rasgo que se ha añadido es que no solo es la imitación de un estilo, sino también de una categoría genérica: la comedia. 


\section{1. Análisis comparativo de los textos}

En adelante, se procede a demostrar la existencia de la relación de hipertextualidad detallada mediante la comparación de fragmentos extraídos de las dos obras que constituyen el corpus de análisis.

Staiger (1966, p. 204) afirma que «un poeta cuanto más inclinado se siente hacia lo cómico, tanto más procura provocar la tensión dramática, pero tan solo como punto de partida para desencadenar la risa, para dispararse luego en meros detalles ridículos». Ubica entre los autores que «se comportan aquí con el mayor desenfreno» a Plauto y a Molière.

Al igual que Plauto, Molière apunta a generar una fuerte tensión dramática. Ello se ve claramente en las intrigas amorosas que presenta en El avaro. La tensión que genera la precipitación de las bodas indeseadas, el embarazo avanzado de Fedria y el robo de la ollita son ejemplos de momentos cargados de tensión en la obra.

Los dos autores utilizan monólogos para presentar a los personajes, que cumplen la función de transparentar el psiquismo de estos. Otra similitud entre las comedias es el predominio del papel del sirviente. En Aulularia, como se dijo, el personaje que permite el avance de la acción es principalmente Estróbilo. En El avaro se destaca el criado Flecha. También ocupa un lugar relevante en la obra Frosina, una joven pobre, que gana dinero manipulando a la gente, adulando, deformando la verdad; es una pícara.

Otro punto en común de las obras es el reflejo de las costumbres, la organización y las creencias de su época, su concepción sobre el matrimonio, el deber de la esposa y la paternidad, incluso las comidas. En los pasajes siguientes se refleja la organización social romana en curias dirigidas por presidentes y la costumbre de ir al foro, lugar donde se celebraba el mercado, los magistrados ejercían su jurisdicción y los tribunales administraban justicia:

Euclión: No ha venido ningún miembro de la curia, ni el presidente, que le tocaba repartir el dinero (Plauto, Aulularia, p. 55).

Euclión: Haz que todo esté a punto cuando regrese del Foro (Plauto, Aulularia, p. 63).

En los parlamentos que siguen, se hace referencia a las pretensiones que comúnmente tenían las doncellas que se casaban, proporcionando una gran dote (pretensiones de púrpura, joyas, carros) y sus ínfulas en el trato cotidiano:

Megadoro: Es, pues, muy justo que tú me des púrpura y joyas, chicos para recados, carros para salir de paseo (Plauto, Aulularia, p. 80). 
Megadoro: No me engañan las buenas casaderas con su orgullo, sus dotes espléndidas, sus gritos, sus deseos de mando, sus carros de marfil, sus metales y su púrpura. Con todos estos dispendios, reducen a sus maridos a la esclavitud (Plauto, Aulularia, p. 54).

También Plauto alude a dos juegos de la época: pintarle la cara a alguien mientras dormía y abrir habas para encontrar sus gérmenes dentro:

Euclión: Pensaba que la Buena Fe era digna de toda confianza y ha estado a punto de pintarme la cara... Está el bosque de Silvano, fuera de las murallas (Plauto, Aulularia, p. 92).

Estróbilo: No es lo que los niños dicen haber encontrado en un haba (Plauto, Aulularia, p. 104).

Se encuentra reflejada en los posteriores fragmentos la posesión absoluta que los amos tenían sobre las personas de sus esclavos, el trabajo de estos últimos y algunos de los peces usados para la preparación de las comidas de entonces:

Ántrax (En la puerta de la casa de Megadoro): Dromón, quita las escamas de los peces; tú, Maquerión, saca las espinas del congrio y de la murena, lo más aprisa que puedas. Yo voy a pedir aquí al lado, a Congrión, la tartera para cocer el pan. Tú, si sabes hacerlo, me vas a dejar ese pollo más fino que un bailarín depilado (Plauto, Aulularia, p. 72).

Estróbilo: ... El esclavo que quiere que su amo esté contento de su servicio, primero debe pensar en su amo, y, en último lugar, en él mismo. Si duerme, que no olvide durante el sueño que es un esclavo. Porque cuando se está al servicio de un amo enamorado, como en mi caso, si se le ve dominado por la pasión amorosa, creo que el deber del esclavo ha de ser el siguiente: retenerle para salvarle... Un esclavo ha de servir de salvavidas para su amo, para evitar que se hunda como el plomo. Han de tenerse bien sabidas las órdenes del amo, de modo que los ojos adivinen lo que su frente piensa. Que lo que él mande, el esclavo se dé prisa en realizarlo, con más rapidez que las veloces cuadrigas (Plauto, Aulularia, p. 85).

Por último, se encuentra reflejada la tradición de realizar ofrendas a los dioses y hacerles peticiones. Un ejemplo es el siguiente fragmento de Euclión: «Ahora acabo de comprar un poco de incienso y estas coronas de flores; serán colocadas en el hogar, en honor de nuestro Lar, para que haga feliz la boda de mi hija» (Plauto, Aulularia, p. 71). 
A continuación, se procede a observar cómo Molière plasma el reflejo de las costumbres y la organización de la época en El avaro. En el próximo pasaje, se muestra el miedo que existía de la reacción social ante el anuncio de un próximo matrimonio:

Valerio: ¡Cómo! ¿Qué podéis temer, Elisa, por los favores que me habéis querido conceder?

Elisa: ¡Ah! Cien cosas a la vez: la cólera de un padre, los reproches de una familia, las censuras de la gente (Molière, 1997, p. 18).

En este parlamento de Cleanto, se manifiesta que en la época era común la participación en juegos de azar: «Me gusta jugar, y como soy muy afortunado, me gasto en vestuario todo lo que gano» (Molière, 1997, p. 24). En este otro diálogo de Cleanto, puede observarse que era común la participación en juegos de azar: «¿Te ha puesto al habla con el que debe prestar el dinero?» (Molière, 1997, p. 30).

Este periodo histórico se caracteriza también por la existencia de adivinadores del futuro:

Frosina: ¡Oh! Leo en vuestros ojos una señal de larga vida!

Cleanto: ¿Eres entendida en esta materia? (Molière, 1997, p. 35).

En el siguiente parlamento de Cleanto, se halla expresada la relación de dependencia de los hijos respecto a sus padres y la autoridad que estos tienen sobre aquellos:

Cleanto: Sí, amo. Pero antes de ir más adelante sé que dependo de un padre y que mi condición de hijo me somete a su voluntad, puesto que no debemos empeñar nuestra palabra sin el consentimiento de quienes nos dieron la vida. El Cielo los hizo dueños de nuestros deseos y nos está ordenado no tratar de realizarlos sin su aprobación (Molière, 1997, p. 19).

En los fragmentos posteriores, se refleja la importancia de las dotes a la hora de decidir la celebración de los matrimonios, las aficiones de las jovencitas (vestidos lujosos, joyas de precio, muebles suntuosos) y algunas comidas de época (caldos, cebadas, leche, queso, manzanas) ${ }^{6}$.

Harpagón: Estoy resuelto a casarme con ella, con tal que cuente con algún patrimonio (Molière, 1997, p. 25).

\footnotetext{
${ }^{6}$ En otros pasajes se nombran comidas de la época: sopas, entremeses, asado, judías, carnero, pasteles, lechones (Cfr. Molière, 1997, p. 41 y p.57). Los nombres de Avena y Merluza de El avaro aluden a alimentos, al igual que el de Congrión de Aulularia. Para mayores detalles sobre la onomástica de Plauto, cfr. Campos Vargas (2012).
} 
Frosina: Es una joven acostumbrada a vivir de ensalada, leche, queso y manzanas, y que no necesitará, por tanto, ni mesa bien servida, ni caldos exquisitos ni constantes cebadas mondadas, ni ninguna de las delicadas fruslerías que reclamaría cualquier otra mujer, y esto no es tan poca cosa que no represente tres mil francos al año, por lo menos. Aparte de esto, le basta con vivir aseadamente y no le gustan los vestidos lujosos, ni las joyas de precio, ni los muebles suntuosos, por los que suspiran tan apasionadamente las de su sexo (Molière, 1997, p. 36).

También Frosina hace la presentación de su oficio de alcahueta, dedicada a obtener dinero de los demás con todo tipo de agudezas:

Flecha: ¡Ah! ¿Eres tú Frosina? ¿Qué vienes a hacer aquí?

Frosina: Lo mismo que hago en todas partes: terciar en asuntos, prestar servicios a las gentes y aprovechar lo mejor posible las pequeñas habilidades que pueda tener... (Molière, 1997, p. 33-34).

Molière pone en boca de Maese Santiago la alusión a dos fiestas religiosas que exigen ayuno por parte de los fieles cristianos: las Vigilias y las Témporas: «El uno dice que mandáis imprimir almanaques especiales, con las Témporas y las Vigilias duplicadas, a fin de imponer doble ayuno a los vuestros» (Molière, 1997, p. 42).

Se encuentran también semejanzas entre las obras en la crítica a profesiones, oficios, etc. Por un lado, en la Aulularia se hallan los siguientes fragmentos:

Estróbilo: Pido por un cocinero, no por un ladrón (Molière, 1997, p. 66).

Ántrax: Pero, ¿Qué son estos gritos que salen de la casa del vecino? Por Hércules, me parece que los cocineros deben estar haciendo de las suyas (Plauto, Aulularia, p. 72).

En estos dos comentarios, se puede apreciar la creencia de la época de que los cocineros eran ladrones. Son una crítica al oficio del cocinero. Por otro lado, en El avaro no solo se hallan críticas a los cocineros, sino también, como ya se resaltó, a los médicos (Cfr. Molière, 1997, p. $21,28)$.

Ambos autores realizan un uso magnífico del lenguaje en los juegos de palabras, el doble sentido, los malentendidos y las exageraciones, entre otros recursos cómicos. Además, utilizan gran cantidad de insultos, refranes y expresiones coloquiales de su época. Un ejemplo de estos usos del lenguaje es el siguiente:

Estáfila: Pero, ¿Por qué me pegas, pobre desgraciada? 
Euclión: Precisamente para que seas una desgraciada y para que tengas una mala vejez, digna de tu maldad (Plauto, Aulularia, p. 45).

Euclión retoma el calificativo que la esclava se ha dado a sí misma para dar lástima a su amo, y lo utiliza para duplicar su crueldad contra ella. También hay en este diálogo una exageración de la maldad de la sierva por parte de Euclión. En este otro fragmento se observa un absurdo, que intensifica el segundo término del par incompatible (vacío): «Toda está llena de vacío» (Molière, 1997, p. 47). En el próximo parlamento de Euclión, hay un juego de palabras del texto latino basado en la expresión ludos facere, que puede significar 'burlarse' o 'pagar los juegos públicos': «Por Pólux, Megadoro, ni lo estoy haciendo, ni aunque quisiera, tendría dinero suficiente para jugar» (Plauto, Aulularia, p. 61). Por último, en el pasaje que sigue hay una aliteración. En latín, 'cobijo seguro' se escribe stabile stablum: «En ninguna parte iba a tener yo un cobijo seguro» (Plauto, Aulularia, p. 47).

Se pasa ahora a ejemplificar el uso trabajado del lenguaje en El avaro, de Molière. Este fragmento contiene un epíteto cómico inventado por Molière: volable en el original. En la traducción al español significaría 'robable'. Este es el diálogo a continuación: «¿Sois acaso un hombre robable, vos, que lo tenéis todo encerrado y que estáis de centinela de día y de noche?» (Molière, 1997, p. 21).

La que sigue es una hipérbole cómica sobre la avaricia de Harpagón, que llega hasta el extremo de ni siquiera usar la palabra dar en el saludo matinal: «No dice nunca os doy, sino os presto los buenos días» (Molière, 1997, p. 34). Otro uso vivo del lenguaje que puede observarse es el de refranes, como los siguientes:

Flecha: Al que le pique, que se rasque (Molière, 1997, p. 23).

Valerio: Hay que comer para vivir y no vivir para comer (Molière, 1997, p. 41).

El siguiente fragmento ilustra el uso del doble sentido. En este caso, Cleanto hace parecer que le produce desagrado la presencia de Mariana, pero sin negar sus sentimientos por ella:

Cleanto: A deciros verdad, padre, no puedo prometeros que me sentiré muy satisfecho de que esa persona se convierta en mi madrastra. Mentiría si os lo dijera. Pero en lo tocante a recibirla bien y a ponerle buena cara, os prometo que cumpliré fielmente vuestros deseos (Molière, 1997, p. 40).

En este otro diálogo a continuación, hay un malentendido provocado por la expresión de Elisa Perdonadme, con la que la joven expresa su desconcierto ante las indagaciones de su 
padre. Este interpreta su expresión como señal de que ella ha oído su discurso precedente. A su vez, este diálogo es una esticomitía.

Harpagón: Y habéis oído, sin duda...

Cleanto: ¿El qué, padre mío?

Harpagón: Eso.

Cleanto: ¿Qué?

Harpagón: Lo que estaba diciendo.

Cleanto: no hemos oído nada.

Harpagón: Cierto que sí.

Elisa: Perdonadme.

Harpagón: Ya veo que habéis oído algunas palabras (Molière, 1997, p. 23-24).

También es posible hallar en las obras de los dos autores que se trabajan aquí numerosas situaciones cómicas, paralelismos cómicos y palizas. Por otro lado, así como Plauto fusiona lo griego con lo romano, Molière realiza alusiones a la antigüedad grecorromana.

Lo expuesto hasta aquí hace referencia a los recursos cómicos, el modo de generar la tensión, el uso del lenguaje y el aprovechamiento del bagaje literario anterior para la propia creación. Un hecho fundamental que une las dos comedias es el personaje que las estructura, al que principalmente se dirige la sátira social: el avaro.

El avaro es una persona poco dispuesta a gastar dinero, que incluso renuncia a comodidades básicas por no hacerlo. En la ficción, la avaricia se exagera hasta el punto de que el avaro es un personaje adinerado y codicioso que vive en la miseria con el fin de ahorrar y tener más dinero acumulado. Tanto en Aulularia como en El avaro esta actitud del protagonista genera problemas en la vida familiar, y es el factor desencadenante de los enredos al complicar las vidas de quienes rodean al avaro.

Molière toma el tipo del avaro de Plauto, que es quien le da forma acabada al personaje originalmente. En efecto, Saulnier (1962, p. 67) afirma que «Harpagón no es tal avaro, es el avaro de todos los tiempos. Pero esto no es decir bastante. Es, sin duda, el avaro tipo: pero si nos interesa a todos es porque el hombre menos avaro es como Harpagón de vez en cuando». Tal es la trascendencia del personaje que perdura en la tradición literaria. 


\section{2. Síntesis}

En la Tabla 1, se exponen las diferencias y similitudes existentes entre las obras, a modo de síntesis:

Tabla 1:

Diferencias y similitudes entre Aulularia y El avaro

\begin{tabular}{|c|c|}
\hline Aulularia & El avaro \\
\hline \multicolumn{2}{|c|}{ Genera una fuerte tensión dramática } \\
\hline $\begin{array}{l}\text { Reflejo de costumbres, comidas, trabajo del esclavo, } \\
\text { creencias, matrimonio, deber de la esposa y paternidad }\end{array}$ & $\begin{array}{l}\text { Reflejo de costumbres, comidas, trabajo del criado, } \\
\text { creencias, matrimonio, deber de la esposa y paternidad }\end{array}$ \\
\hline \multicolumn{2}{|c|}{ Estilización del lenguaje: juegos de palabras, refranes, doble sentido, malentendidos. } \\
\hline Personajes tipo & $\begin{array}{l}\text { Personajes convencionales, pero con cierta profundidad } \\
\text { psicológica }\end{array}$ \\
\hline \multicolumn{2}{|c|}{ Exageraciones, palizas, repeticiones de efectos, ingenio grosero, situaciones cómicas, bromas y arrebatos de } \\
\hline \multicolumn{2}{|c|}{ Tema: avaricia del protagonista, que consume su vida y altera la del resto. } \\
\hline Ambiente: Roma & Ambiente: París \\
\hline \multicolumn{2}{|c|}{ Monólogo, predominio del papel del esclavo/criado } \\
\hline \multicolumn{2}{|c|}{ Crítica a ciertas profesiones/oficios } \\
\hline Apelaciones al público & No realiza apelaciones al público \\
\hline No posee personajes que adopten una falsa identidad & $\begin{array}{l}\text { Presenta personajes que adoptan una falsa identidad } \\
\text { (Valerio y Anselmo) }\end{array}$ \\
\hline Fusión de lo heleno con lo romano & Alusiones a la antigüedad grecolatina \\
\hline \multicolumn{2}{|c|}{ Personaje principal y objeto de la sátira: el avaro } \\
\hline
\end{tabular}

\section{Conclusiones}

Este artículo gira en torno a la idea de que toda obra posee la característica de la transtextualidad, que implica que toda obra es trascendente de su propio texto y lleva en sí literatura anterior, al mismo tiempo que se une a la red literaria para que, sobre él, se tejan nuevos textos a lo largo del tiempo. 
Las dos comedias que se analizaron comparativamente aquí son Aulularia, de Plauto y El avaro, de Molière. Las obras son semejantes, en primera instancia, por tener como protagonista y blanco de su crítica social al personaje tipo del avaro. Por otro lado, las similitudes formales entre las comedias son numerosas. En primer lugar, ambas obras generan una intensa tensión dramática. Además, reflejan creencias y costumbres (comidas, trabajo esclavo/servil, matrimonio, deber de la esposa, la paternidad). Ambas obras hacen una explotación magistral del lenguaje: exageraciones, ingenio grosero, bromas y arrebatos de insultos, monólogos.

Otras características comunes a las dos comedias son el uso de personajes tipo, las palizas, situaciones cómicas, críticas a determinados oficios/profesiones y predominio del papel del esclavo. Es interesante, además, considerar que ambas obras retoman lo antiguo y clásico: Plauto, lo heleno; Molière, lo grecorromano. Por último, el tema que estructura las obras es el mismo, aunque las historias tengan algunas diferencias.

La relación que se establece entre las obras es la de hipertextualidad indirecta o imitación. En particular, esta imitación pertenece a un régimen serio o forgerie. Esta especie de imitación se caracteriza por contener los mismos rasgos estilísticos del original, pero sin hacer patente de modo explícito su carácter imitatorio. Por otro lado, por tratarse de una relación hipertextual, la forgerie supone la relación architextual, i e., la imitación de determinados rasgos genéricos, en este caso, de la comedia.

La causa de la existencia de una relación de hipertextualidad entre las obras es, principalmente, la arquetipicidad propia del mundo antiguo. En efecto, el movimiento al que perteneció Molière, el Neoclacisismo, es un movimiento humanista que sigue la guía de los antiguos porque a ellos se les concede una sabiduría más profunda y esencial que a los contemporáneos.

\section{Referencias bibliográficas}

Bayet, J. (1975). Literatura latina. Pról. J. Clota. (4ª ed). Barcelona: Ariel.

Bernardi, C. \& Susa, C. (Eds.). (2008). Storia essenziale del teatro. Milán: Vita e Pensiero.

Campos Vargas, H. (2011). «Por qué y cómo de la onomástica en la Aulularia de Plauto (254 a. c. -184 a. c) ». Káñina, Rev. Artes y Letras, 35 (1), 19-25.

Chávez Robledo, P.; García Guerrero, J.; Piedra Noriega, I.; García Bruce, C; González Treviño, J. (2009). «La ética médica en la obra de Molière». Avances, 6 (19), 38-48. 
Domenech, R. (1967). «Molière». En: Cuadernos Hispanoamericanos, 215, 420-428. Recuperado de http://www.cervantesvirtual.com/nd/ark:/59851/bmcnp2p1 Consulta: 24 de julio de 2016.

Friedrich, H. (1973). Humanismo occidental. Trad. R. Gutiérrez Guirardot. Buenos Aires: Sur.

Fontán, A. (1974). Humanismo romano. Barcelona: Planeta.

Garçon, M. (1979). «Luis XIV es Molière? » Trad. J. Farrut. Revista Historia, 97, 98-119.

Genette, G. (1962). Palimpsestos: La literatura en segundo grado. Trad. C. Prieto. Madrid: Taurus.

Molière. (1997). «El avaro» En: Teatro. El enfermo imaginario, El burgués ennoblecido, El avaro, Las mujeres sabias. México: Editores Mexicanos Unidos, 17-65.

Jordan, P. (2010). «In Search of Pantalone and the Origins of the Commedia dell'Arte». Revue internationale de philosophie, 2 (252), 207-232.

Plauto. (1968). Comedias: Aulularia, Anfitrión, Rudens. Trad. E. Farrés. Barcelona; Bruguera.

Schmitt, N. (2004). «Commedia dell'Arte: characters, scenarios, and rhetoric». Text and Performance Quarterly, 24 (1), 55-73.

Saulnier, V. (1962). La literatura francesa del siglo clásico. Trad. E. Schoo. Buenos Aires: Editorial Universitaria de Buenos Aires.

Staiger, E. (1966). Conceptos fundamentales de poética. Trad. J. Ferreiro. Madrid: Rialp.

Valverde, J. (1984). Movimientos literarios. (2a . reimpr.). Navarra: Salvat.

Esta obra está bajo una licencia de Creative Commons Reconocimiento-NoComercial-SinObraDerivada 4.0 Internacional 